\title{
Better Buses Equity Assessment Project Recommendations for New York City Department of Transportation (NYC DOT)
}

\author{
Ayesha Lilaoonwala, New York University, United States \\ Caroline Morris, New York University, United States \\ Maitri Pujara, New York University, United States \\ Rachel Brown, New York University, United States \\ William Sklar, New York University, United States
}

\begin{abstract}
The New York City Department of Transportation (NYC DOT) initiated the Better Buses Action Plan in 2019 to improve the speed of buses throughout New York City (NYC) by $25 \%$ and increase the number of bus riders by the end of 2020. Although the COVID-19 crisis impacted these plans, DOT launched the Better Buses Restart Program. NYU's team evaluated DOT's project selection methodology through an equity lens to determine if DOT's Better Buses projects are equitably distributed and assess whether DOT could do more to reach equity populations. The team conducted a comparative analysis of equity initiatives in other US cities, analyzed the needs of equitable populations, and evaluated how to serve these populations through its project selection, planning, engagement, and evaluation practices. The team conducted stakeholder outreach through the distribution of a survey as well as a roundtable discussion. Furthermore, the team developed interactive maps to visualize the priority bus routes with demographics by census tract to show existing disparities in transportation experiences for equity populations within NYC. The final report includes recommendations for how to improve the inclusion of equity in the better buses program.
\end{abstract}

\section{Keywords}

Transportation Planning, Equity, Equitable Populations, Community Development, and Better Bus Services

\section{Introduction}

\subsection{Project Objectives}

Public bus service is a critical transportation option in New York City (NYC). It provides access to opportunity and essential services, allowing residents to live fulfilling lives without a personal vehicle. Yet, unreliable and slow service caused a $16.6 \%$ bus ridership decline from 2014 to 2019 . The preliminary objective of this research is for the New York City Department of Transportation to confirm that the benefits of its investments are accruing to underrepresented or disadvantaged populations fairly and effectively. Another objective is to gain a better understanding of the different issues facing these groups, so that NYC DOT may target its improvements appropriately. 
For this study, NYU's team elected to focus on those populations who are among the most reliant on bus transit services. The team is using the following definition for 'equity' and 'equity populations' concerning bus systems: An equitable bus system provides transportation that is reliable and affordable, clean and safe, has extended hours of services, and improved connections to the education, work, and healthcare opportunities that disadvantaged populations and frontline workers need. The system would also ensure that capital and service investments are directed toward improving the outcomes for, but not limited to, the equity populations identified below:

Low-income populations: Residents of low-income neighborhoods rely heavily on bus services and often face issues regarding limitations in the provision of transport services, frequency, timing, and reliability of transportation services as well as the range of places served.

People of color: New York City has significant gaps in access to high-quality transportation options, especially for communities of color who often live in low-income neighborhoods.

Frontline workers (workers who provide direct-services: employees in the grocery, pharmacy, transit, delivery \& storage, cleaning, healthcare, and social services industries): During the COVID-19 pandemic, frontline workers continued traveling to and from work daily, with many not securing high enough salaries to afford to do so without public transportation.

People with disabilities (people with hearing, vision, self-care, cognitive, independent living, and ambulatory difficulties): People with disabilities travel less frequently and rely on public transportation more than the general population.

\subsection{Methodology}

The final assessment, recommendations, and results from a comprehensive study include the best practises comparison, stakeholder survey, roundtable discussion with advocates, and GIS data analysis. The team reviewed current approaches to equitable bus planning and public outreach in several other American cities. The following cities have exemplary bus planning practices that can be adapted by NYC DOT: San Francisco, CA; Denver, CO; Portland, OR; and Oakland, CA. The key findings serve as national benchmarks of effort and commitment to equitable outcomes in transit. The preliminary data was collected through structured survey for stakeholders of the Better Buses Action Plan distributed to members of NYC DOT's Better Buses Advisory Group to better understand the needs of the targeted populations of equity in NYC. In addition to this, the team conducted a roundtable discussions with stakeholders to provide further insight into the topics covered in the survey. Lastly, the team used Tableau and ArcGIS data visualization software to create maps and other infographics with data collected from the American Community Survey (ACS), ASTAR CDC's SVI, MTA, and NYC DOT to visualize the current bus frequency and reliability, geographic distribution of the selected focus groups, and demographics surrounding NYC DOT's bus corridors.

\section{Findings and Analysis}

\subsection{Key Takeaways from Best Practices Comparison}

\subsubsection{Neighborhood-Based Approach}

In San Francisco, the San Francisco Municipal Transportation Agency (SFMTA) operationalized its equity goals by identifying neighborhoods that were home to populations it considered underserved by transit or otherwise marginalized. By doing this, it was better able to target outreach efforts and more efficiently work to understand the issues faced in these communities. 


\subsubsection{GIS Tools and Project Prioritization}

In Denver, the Regional Transportation District (RTD) implemented a GIS tool that allows the agency to visualize the equity populations that would be served by proposed bus rapid transit (BRT) routes. This tool is interactive and can be refined to select corridors where user-defined thresholds for socioeconomic factors are met. For example, it can highlight corridors with high numbers of people with disabilities or lowincome households. Should NYC DOT adopt a similar tool, it could allow for a more detailed and userfriendly bus priority project scoring matrix for equity considerations.

Another innovative practice being used in Denver is the Blueprint Denver Equity Index. This is another mapping project that allows transportation planners and other city planners to better understand the spatial distribution of equity factors such as the social determinants of health and access to transit.

In Oakland, the Department of Transportation (OakDOT) developed a Geographic Equity Toolbox (GET) that is used to identify areas with high concentrations of underserved populations. The GET compares the demographic characteristics of each census tract in the city against the citywide averages for those characteristics and priority score are given accordingly. Each equity measure within a census tract is weighted and all measures are aggregated to give a census tract its total priority score. Race and income are each weighted as $25 \%$ of the score while education, single-parent families, old age, disabilities and rent burden are each weighted as $10 \%$ of the score. The ranked census tracts (priority neighborhoods) are then further aggregated into Oakland's nine Planning Areas (comparable to New York's Community Districts or Neighborhood Tabulation Areas) to arrive at a population-weighted Planning Area Score. These Planning Area Scores are consulted for program funding allocation decisions and in developing community outreach strategies.

Specifically, funding for certain projects is allocated in part by a planning area's share of citywide underserved populations. For OakDOT's Pavement Prioritization Plan for 2019-2021, 85\% of the local streets portion of the program's funding was distributed based on a prioritization methodology that gave equal weight to street conditions and equity measures within the planning areas. This project selection methodology ensures that funding for street improvement projects is going to areas that need the most.

\subsubsection{Racial Equity Plan}

The City of Portland uses a racial equity framework across all bureaus. The Portland Bureau of Transportation (PBOT) is cognizant of the marginalization of other groups of people based on gender, sexual orientation, ability and age, to name a few but focusing on racial equity provides the opportunity to introduce a framework, tools and resources that are transferable to other areas of marginalization. A racial framework can clearly distinguish the differences between individual, institutional, and structural racism and the history and current reality of inequities can be applied to other groups.

In Oakland, OakDOT has a dedicated Racial Equity Team whose mission is to increase transparency and hold OakDOT accountable for racial equity issues in transportation. OakDOT's Strategic Plan envisions "a more equitable city, where resources are spent in the communities that need them most to lower the cost of transportation, improve access to jobs and education, and engage with neighborhoods like never before." OakDOT seeks to prioritize equitable project resource distribution and to enhance its use of data to guide equitable mobility and infrastructure investments.

\subsection{Key Takeaways from Stakeholder Outreach}

To better understand the needs of the targeted populations of equity in NYC, the team administered an online survey to available members of the Better Buses Advisory Group (BBAG) and community boards that 
represent bus-reliant neighborhoods. All respondents either strongly (66.6\%) or somewhat (33.3\%) agreed that NYC DOT's bus priority toolkit improves service. The transit advocacy stakeholders surveyed by the team evaluated the quality of bus service in NYC as mediocre when considering accessibility, frequency, reliability, and comfort. However, they ranked the safety of bus service as best. Additionally, they reported that the investments that NYC DOT made through its Better Buses initiative have led to visible improvements. The stakeholders proposed suggestions for future projects, including an emphasis on coordination with the community and other agencies, expansion of digital outreach, incorporation of a comprehensive project selection approach, improvement to bus lane enforcement, and prioritization of bus service as a first class mode of transportation equal to the subway.

\subsection{Key Takeaways from Roundtable Discussion}

On March 30, 2021, the team held a roundtable discussion with representatives from several transit and equity advocacy organizations of NYC, who previously participated in the online survey. The roundtable discussion served as a follow-up to the survey to have a more interactive and detailed conversation around the topic of equity in New York City buses. There was consensus among the participants that bus service is essential for equity populations. Since they make up a large percentage of NYC bus riders, investments in improved bus service are equity investments. The participants agreed that the city should be doing more to create an equitable system where bus service is treated as vital, and of equal importance to the subway. A more predictable and reliable system will be beneficial for equity populations. Furthermore, by not making investments in improving bus service, the City is incentivizing a more car-oriented economy, which places an additional financial burden on equity communities.

\subsubsection{Methods for Engaging with Equity Populations}

In terms of public outreach and participation, roundtable participants noted that low-income populations are the hardest to reach. Some organizations hold regular rider meetings in multiple languages to better understand their needs. The participants also were generally in favor of increasing opportunities for online engagement with bus riders, and noted the progress made with online engagement since the start of the COVID-19 pandemic. One suggested that posting QR codes on buses and at bus stops would make it more convenient for riders to complete surveys and get information about potential or ongoing projects. However, many lower-income and older people may not have smartphones. These populations would have to be reached by other means, such as through community organizations. With the rollout of the MTA's One Metro New York (OMNY) fare payment system, there is an opportunity for technology sharing between the MTA and NYC DOT. In-person engagement at bus stops and on the buses, is also valuable and can help build goodwill between NYC DOT and bus riders. One limitation of in-person engagement noted that the data collected is skewed to riders that use the bus during normal work hours. If in-person engagement is only collected during the day, feedback from evening and late-night riders are not captured.

\subsubsection{Criteria for choosing Priority Bus Corridors}

The participants agreed on the importance of prioritizing equity communities, including low-income, people of color, people with disabilities, and frontline workers, as well as environmental justice areas, located near heavy highway traffic, power plants or other pollution sources. One participant highlighted the importance of taking a comprehensive approach to project selection, and looking at bus priority improvements on a system-wide, not ad hoc, basis. They elaborated to say that a system-wide planning approach is less likely to invite not-in-my-backyard (NIMBY) opposition. In addition to this, NYC DOT has done a good job of being transparent about the Better Buses projects, the online presentation of this information could be simplified to make it easier to find and understand. 


\subsubsection{Dealing with Opposition to Bus Projects}

Roundtable participants noted that the public participation process sometimes leads to lawsuits by bus critics that delay valuable projects because there is a disparity between those who have the resources and time to attend in-person public meetings and those who would benefit the most from bus priority projects. However, to date, the courts have found bus priority projects to be in the Commissioner's legal authority and that most lawsuits are without merit.

\subsubsection{The impact of the COVID-19 Pandemic on Bus Riders}

Since the beginning of the COVID-19 pandemic, it has become increasingly clear that buses are essential to equity populations, and participants expressed a hope that the City will use the momentum made on the bus system during the pandemic to increase investment. Another discussion point worth noting from the roundtable was the need for improved bus lane enforcement. Parked vehicles in bus lanes are a major problem and automated enforcement can help reduce violations.

\subsection{Geographical Data Analysis}

\subsubsection{Existing Condition in New York City}

White workers have a lower average commute time than workers of color. Asian/Pacific Islander (PI), Black, and Hispanic workers all have average commute times longer than the citywide average of $\mathbf{4 0}$ minutes. Commute times for Black workers are significantly longer than all other groups: Black workers have an average commute time 10 minutes longer than White workers.

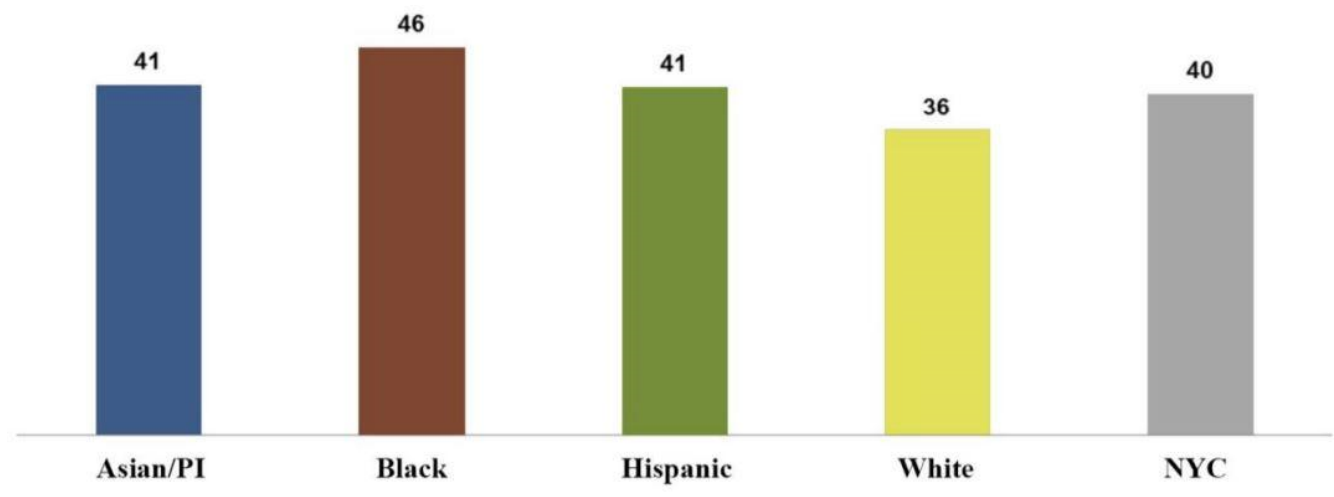

Figure 1. Travel Time to Work, by Race/Ethnicity ${ }^{1}$

The racial/ethnic gap in commute time has not narrowed over time. The figure shows the persistent discrepancy between the average commute time of White and non-White workers since 1990. Average commute length grew for all commuters since 1990. The gap in average commute time ranges from 5 minutes to 8 minutes and does not appear to be narrowing.

1 Dataset Source: American Community Survey (ACS).(2015-2019). Table B02001.Race and Ethnicity[Online]. Availabe at: https://data.census.gov/cedsci/table?q=Race\%20\&tid=ACSDT1Y2019.B02001 (Excluded if a worker worked at home, persons under 16 years, not in the labor force, unemployed, employed with a job but not at work) 
White People of color

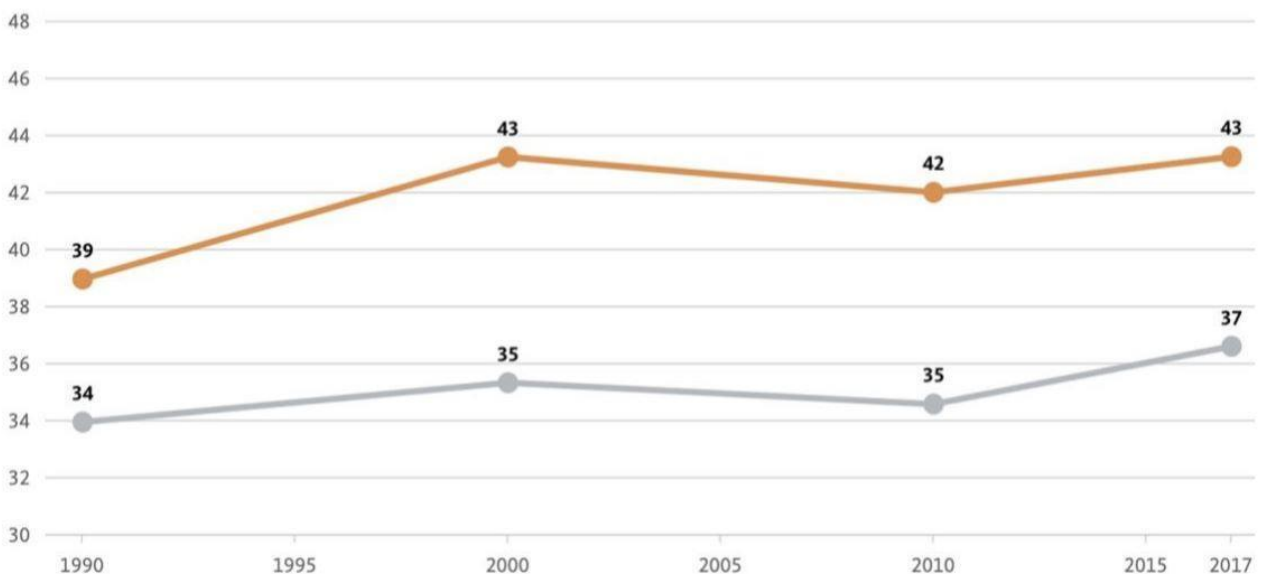

Figure 2. Average travel time to work (minutes) by race/ethnicity: New York City (1990-2017)²

People of color are more reliant on the bus to get to work. $16 \%$ of Black and $14 \%$ of Hispanic workers use the bus to commute, which is twice the proportion of White workers who commute via bus (7\%). Similar patterns exist for workers with disabilities. Workers with a disability have a longer average commute at 43 minutes compared to 40 minutes for workers without a disability. $15 \%$ of these workers use the bus to commute, compared to the citywide average of $11 \%$. This difference may be related to differences in accessibility between subways and buses. Currently, only approximately $25 \%$ of subway stations are accessible by ADA standards.

Commute times for frontline workers have not been widely studied. Research by the NYC Comptroller's Office suggests that frontline workers are more reliant on the bus than workers in non- essential industries. In total, frontline workers account for $30 \%$ of regular, pre-pandemic bus commuters and $20 \%$ of subway commuters, as well as $11 \%$ of rail commuters. This may help to explain why bus ridership has seen a smaller drop (70\%) than the subway (87\%), LIRR (76\%), and Metro-North (94\%) with the spread of COVID-19 in New York City.

The proportion of residents that use the bus as their primary mode of transportation to and from work is a helpful indicator for where improved bus service would have a high impact. Bus commuters are geographically concentrated. New Yorkers living in central Brooklyn, southeast Queens, parts of the Bronx, and Staten Island are likely to rely on buses when commuting to work. 


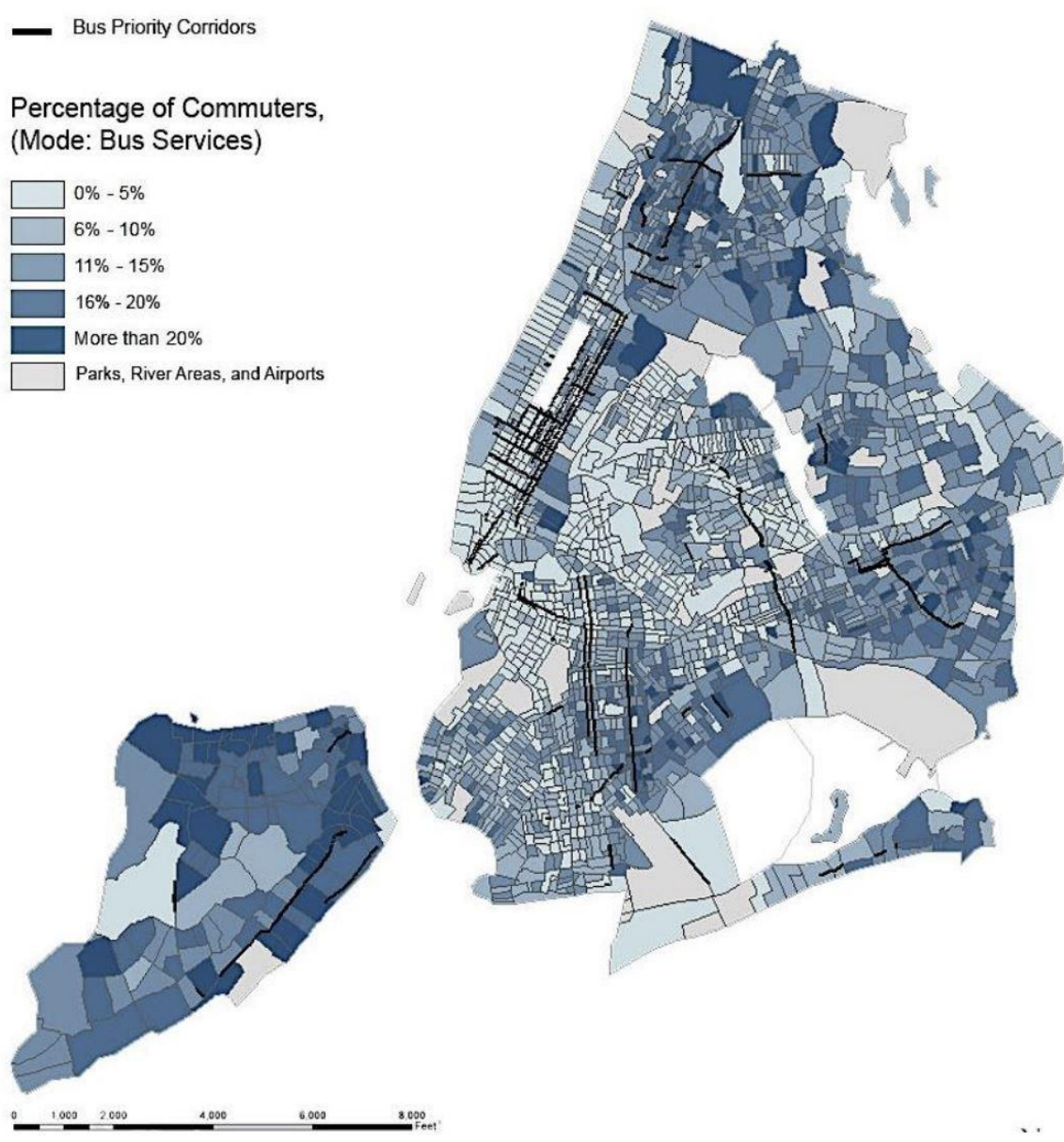

Figure 3. Proportion of Workers using the Bus to Commute in NYC, by census tract (2015-2019)

Furthermore, bus commuters are among the most economically vulnerable living in New York City, with lower average incomes and less education than subway commuters and average city residents. The average annual income of bus commuters is $\$ 28,455$ which is far lower than subway commuters $(\$ 40,000)$. Nearly $70 \%$ of bus commuters do not have a bachelor's degree, $12 \%$ are over $60,42 \%$ have children at home, $17 \%$ are single parents, $55 \%$ are foreign born, and $75 \%$ are people of color which is significantly higher than subway commuters.

\subsubsection{Program Alignment with Equity Goals}

This section analyzes the demographics surrounding bus lane projects using the CDC's SVI (which is derived from census data). The team examined the rates of poverty, disability, and the proportion of people of color who reside in census tracts that bus lanes pass through (example below), and compared them to citywide and borough-wide residential averages. A higher than citywide average proportion of equity populations residing along a bus corridor indicates that the corridor is serving those populations, and therefore NYC DOT is achieving its goal of serving equity populations. If the census tract proportions are similar to citywide or borough-wide averages, this indicates that NYC DOT is serving equity populations at the same or a similar rate to all citizens. This would mean that NYC DOT is not achieving its goal of focusing specifically on the most vulnerable populations.

3 Dataset Source: U.S. Census Bureau, American Community Survey (ACS). (2015-2019). Table B08301 Means of Transit[Online]. Availabe at: https://data.census.gov/cedsci/ (Areas with no population or no data available are excluded.) 
A limitation of this analysis is that it relies on residential data and therefore does not take into account bus lanes that experience high usage by equity populations outside of the neighborhoods in which they live. Ridership data disaggregated by demographics would be the ideal way to determine routes used by equity populations, but that data does not exist and is unlikely to exist in the future due to privacy issues. Due to the irregular shapes of census tracts and bus lane paths, some parts of the census tracts included in the analysis for a given bus lane are a significant distance from the bus lane. Additionally, a 'five minute walk' varies based on ability, and the $1,320 \mathrm{ft}$. used to approximate a five minute walk may take certain populations longer than five minutes to traverse. In addition, when the five minute walk buffer is added, additional census tracts are captured in the demographic analysis that are located even farther from the bus lane.

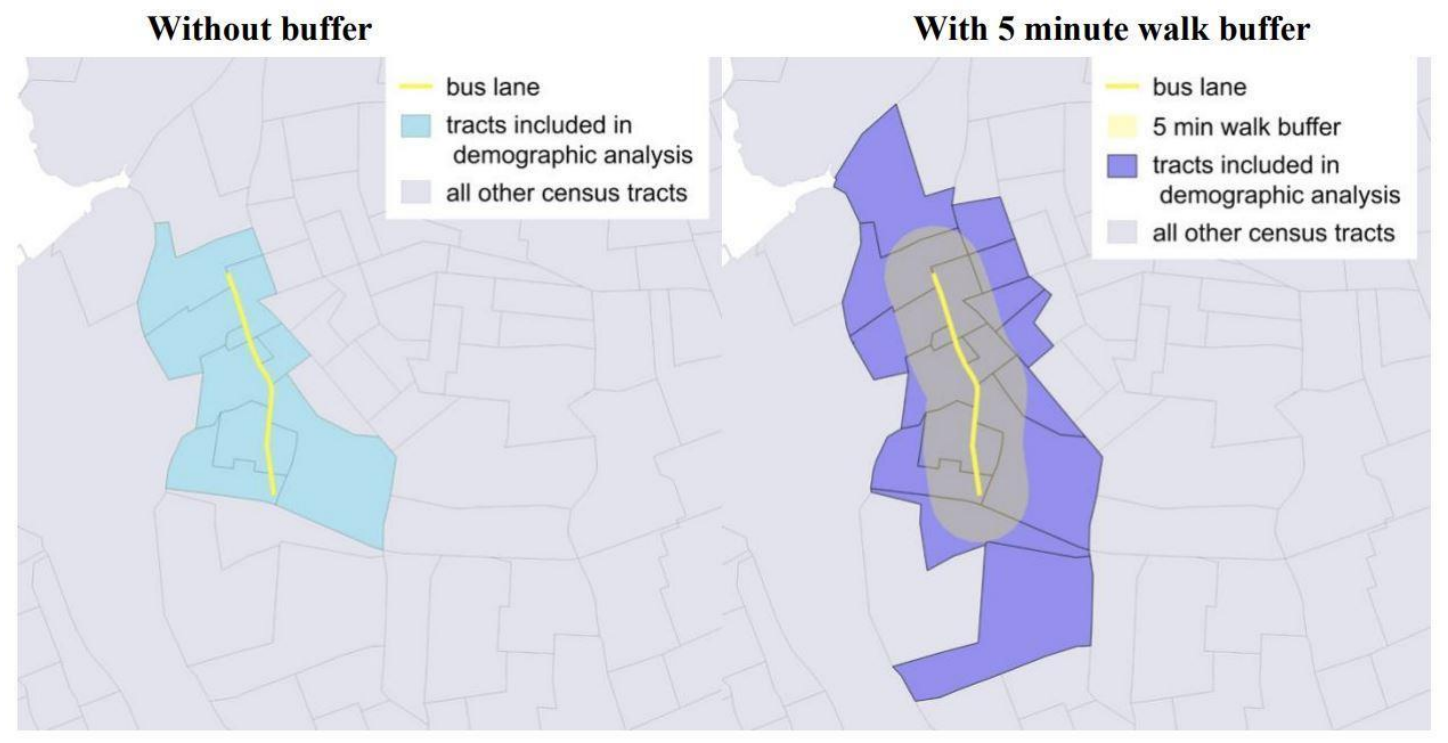

Table 1. Example: Census tracts captured in Demographic Analysis in Main Street, Queens ${ }^{4}$

\subsubsection{Bus Lanes and Equity Population Analysis}

The demographics of census tracts with bus lanes are similar to citywide averages for the percentage of people living in poverty and people with a disability, meaning that these populations are served at a similar rate as all New Yorkers. The equity population that stands out as being particularly underserved is communities of color: the percentage of people of color who live in census tracts with bus lanes $(62 \%)$ is lower than the citywide average (68\%). This means that NYC DOT bus corridors projects are disproportionately located in neighborhoods with a lower population of people of color than the citywide average. When a five minute walk buffer $(1,320 \mathrm{ft}$.) is added, the proportion of residents of color within the bus lane condition increases to $66 \%$, but still below the citywide average of people of color.

\footnotetext{
${ }^{4}$ Dataset Source: NYC DOT, Bus Lane Inventory and Bus Priority Corridors Dataset, Centers for Disease Control and Prevention. Social Vulnerability Index[Online]. Availabe at: https://www.atsdr.cdc.gov/placeandhealth/svi/documentation/SVI_documentation_2018.html 


\begin{tabular}{|c|c|c|c|}
\hline \multicolumn{2}{|c|}{ New York City Existing Bus Corridors } \\
\hline $\begin{array}{c}\text { Equity } \\
\text { population }\end{array}$ & $\begin{array}{c}\text { Percentage living in } \\
\text { census tract containing a } \\
\text { bus corridor }\end{array}$ & $\begin{array}{c}\text { Percentage living in census } \\
\text { tract within a 5 minutes' } \\
\text { walk of a bus corridor }\end{array}$ & $\begin{array}{c}\text { Percentage of NYC } \\
\text { population }\end{array}$ \\
\hline $\begin{array}{c}\text { In poverty } \\
\text { With a } \\
\text { disability }\end{array}$ & $\mathbf{1 8 . 1 9}$ & $\mathbf{1 9 . 0 3}$ & $\mathbf{1 8 . 6 0}$ \\
\hline $\begin{array}{c}\text { People of } \\
\text { color }\end{array}$ & $\mathbf{1 0 . 4 1}$ & $\mathbf{1 0 . 4 5}$ & $\mathbf{1 0 . 7 3}$ \\
\hline
\end{tabular}

Table 2.percentage of Equity Populations Served by Existing Bus Corridors ${ }^{5}$

The highlighted green color indicates that the percentage of residents who are defined as the equity population living in the given bus lane condition (e.g., within a census tract containing the five minute buffer) is higher than the citywide percentage of residents defined as that equity population. Whereas white color indicates the percentage slightly lower but similar to the citywide average is served within that category and red color indicates a gap greater than $1 \%$ between the citywide average of that category and the percentage of equity population within the given bus lane condition.

\section{Recommendations}

\subsection{Project Selection}

NYC DOT should increase the weight of equity considerations in its priority corridor ranking system to ensure that technical factors, professional judgment, and political considerations do not outweigh equity considerations. To ensure a substantial emphasis on serving this diverse spectrum of equity populations, the team recommends that equity characteristics should be increased, putting social equity factors on equal footing with the physical categories of service, performance and feasibility. One way to approach this modification to the scoring system is to develop a GIS tool similar to what has been implemented in Oakland with its Geographic Equity Toolbox and Denver with its Bus Rapid Transit Equity Analysis. Such a tool can be used to pinpoint neighborhoods or census tracts that rank highly on any number of equity characteristics as compared to citywide averages. NYC DOT can use the CDC's SVI to identify priority areas, or it can make a customized index, as Oakland has done. Priority areas can also be weighted by population. The team developed an interactive geospatial tool in Tableau (an interactive data visualization software) to serve as a starting point for NYC DOT to analyze the priority corridors against the equity factors of the SVI. ${ }^{6}$

SVI ranks census tracts by comparing their demographics to statewide averages on 15 social factors. The four major themes included in the Tableau are: Socio-economic factors (poverty level, employment, education), Household composition \& disability (young and old, disability status, single-parents), Minority status \& language (non-White population and low English proficiency), and Housing type (multi-family, crowded housing, car-free households). Using this tool, NYC DOT can assess whether a bus priority

\footnotetext{
${ }^{5}$ Dataset Source: New York City Department of Transporattion. (2020). Bus Lane Inventory Dataset[Online]. Availabe at: https://www1.nyc.gov/html/dot/html/about/datafeeds.shtml

6 You can refer the developed interactive geospatial tool link in the reference section.
} 
candidate corridor will serve a variety of equity populations. This assessment can then be incorporated into the scoring matrix for the candidate corridors. The fully built-out version of this tool should add the bus routes that use each candidate corridor and should overlay the corridors, routes, and census tracts on a single map to allow for rapid evaluation of any bus priority candidate corridor.

Also, NYC DOT should allocate a significant portion of bus priority funds to projects that disproportionately serve equity populations. As demonstrated by Oakland, there is precedent for allocating a portion of funds to projects that disproportionately serve equity populations. Within that allocation, funds are later distributed among priority areas according to their share of miles of streets with a physical need for improvement, as well as their share of equity populations. The remaining funds could be used for discretionary projects distributed across the city. To some extent, all investments in bus priority measures will impact equity populations, as overall bus ridership skews toward equity populations. However, to further promote the inclusion of equity populations in the Better Buses Plan, NYC DOT should consider adopting a similar funding distribution system to that used in Oakland. Currently, there is a lack of data on ridership demographics for specific bus routes. The best approximation of ridership demographics would be to use available data on where equity populations live and work and classify routes that pass through those neighborhoods. Allocating a large percentage of funds to projects that are scored on a standardized scale with more weight given to equity than the current, while still reserving some discretionary funds, will help NYC DOT meet its bus equity goals fairly and objectively.

\subsection{Project Engagement}

The review of current Better Buses projects shows that NYC DOT has already started using technology to solicit stakeholder feedback. This includes interactive maps and surveys posted on social media and through QR codes at bus stops. These tools are increasingly accessible to the general public and should be expanded to all planned projects moving forward. NYC DOT can expand its engagement with riders by optimizing outreach through online meetings and forums. These platforms help work towards the NYC DOT's equity goals to reach all rider populations easily and provide outlets for them to communicate with the agency. The team suggests expanding the use of QR codes at bus stops and in buses for riders to provide feedback about their experiences. By facilitating and easing paths of engagement, riders might be more likely to share positive or negative experiences. Additionally, the implementation of OMNY for fare collection on riders' smartphones could serve as a means of receiving brief information including riders' satisfaction through a pop-up survey after they scan onto a bus. The stakeholder discussions shed light on the value of hosting regular community meetings to encourage consistent, accessible engagement. Particularly during the COVID-19 pandemic, it is evident that there are benefits of conducting meetings online through different platforms. This practice is advantageous and should be continued even after the pandemic because it allows participants to attend from anywhere and increases accessibility. To better understand the needs of equity populations, NYC DOT should also expand its existing model to include local organizations who work in direct service to equity populations.

\subsection{Project Evaluation}

NYC DOT should measure changes in bus speeds, on-time performance and bunching. This information should be easily accessible to riders at bus stops and online. NYC DOT should also continue its engagement with riders after implementation of bus priority projects to ensure that their needs have been met and to gain insight into future projects. NYC DOT's project selection criteria should be re-evaluated routinely to ensure that corridors that disproportionately serve equity populations are being selected more often. If 
NYC DOT finds that bus transit conditions are improving for equity populations no additional modifications to the project selection criteria should be necessary.

\subsection{Conclusion}

The paper presents recommendations to achieve equitable outcomes through project selection, public outreach and project evaluation. Establishing a strong transportation equity community partnership program and optimizing technology to facilitate engagement with bus riders will allow NYC DOT to gather more precise ridership data and better target projects that serve disadvantaged bus riders. In general, NYC DOT has done fairly well at reaching equity populations with its past projects. The recommendations of this paper should serve as a guide for NYC DOT to integrate a more intentional equity approach into its future Better Buses projects. However, NYC DOT does not have control over the design of the bus network, fares, or scheduling, all of which could have a significant influence over equitable outcomes.

Moving forward, NYC DOT should make sure that it emphasizes its commitment to equity in its partnership with the MTA. A strong interagency partnership committed to equity will lead to a reliable bus network for all New Yorkers. The needs of bus riders can evolve, and and NYC DOT needs to remain adaptable to the circumstances facing equity populations. To continue making progress serving the transportation needs of equity populations, NYC DOT should increase public transparency by publishing an accessible annual report detailing changes in bus performance as a result of its Better Buses projects. 


\section{References}

American Association of People with Disabilities (2015). Equity in Transportation for People with Disabilities[Online]. Available at: http://www.civilrightsdocs.info/pdf/transportation/final-transportationequity-disability.pdf

Centers for Disease Control and Prevention (2018). Social Vulnerability Index[Online]. Available at: https://www.atsdr.cdc.gov/placeandhealth/svi/documentation/SVI documentation 2018.html

City and County of Denver Department of Community Planning and Development (2019). Blueprint Denver-Appendix C: Equity Concepts Methodology[Online]. Available at: https://www.denvergov.org/content/dam/denvergov/Portals/Denveright/documents/Blueprint/CKey Eq uity Concepts Methodology.pdf

Diaz, C. (2020). Infographic: How Much Of The NYC Subway Is Accessible?[Blog]Gothamist. Available at: https://gothamist.com/news/infographic-how-much-nyc-subway-accessible (5 March 2020).

Goldbaum, C. (2020) 'Subway Service Is Cut by a Quarter Because of Coronavirus', The New York Times (Daily Edition), 24 March [online]. Available at:

https://www.nytimes.com/2020/03/24/nyregion/coronavirus-nyc-mta-cuts-.html.

Guse, C. (2021). 'NYC to launch a busway in Flushing after local pushback sparked months of delays.' NY Daily News (Daily Edition), 13 January [online]. Available at:

https://www.nydailynews.com/new-york/ny-flushing-queensbusway-nyc-20210113vcynqvptknaujkz3ydmrmq67me-story.html

Headwaters Economics and Regional Transportation District (2019). RTD Bus Rapid Transit Study - Equity Analysis[Online]. Available at:

https://headwaterseconomics.org/equity/disadvantaged-populations/denver-transit-equity-analysis/

Metropolitan Transportation Authority. (2020). Subway and bus ridership for 2019[Online]. Available at: https://new.mta.info/agency/new-york-city-transit/subway-bus-ridership-2019

New York City Department of Transportation. (2016). Strategic Plan 2016 [Online]. Available at: https://www.nycdotplan.nyc/sites/default/files/2017-07/Strategic-plan-2016.pdf

New York City Department of Transportation. (2021). Better Buses[Online]. Availabe at: https://www1.nyc.gov/html/brt/html/betterbuses/betterbuses.shtml. 50

City of Oakland Department of Transportation. (2020). Oakland Geographic Equity Toolbox and Equity Map: Methodology and Literature Review[Online]. Availabe at:

https://www.oaklandca.gov/resources/oakdot-geographic-equity-toolbox

City of Oakland Department of Transportation. (2019). Three Year Pavement Prioritization Plan[Online]. Availabe at: https://www.oaklandca.gov/resources/2019-paving-plan 
City of Oakland Department of Transportation. (2019). Strategic Plan[Online]. Available at: $\underline{\text { https://cao- }}$ 94612.s3.amazonaws.com/documents/oak060949.pdf

Office of the New York City Comptroller. (2020). 'New York City's Frontline Workers', Office of the New York City Comptroller[Online]. Available at: https://comptroller.nyc.gov/reports/new-york-citysfrontlineworkers/.

Portland Bureau of Transportation. (2021). Equity Matrix.The City of Portland, Oregon[Online]. Availabe at: https://www.portlandoregon.gov/transportation/74236

Pujara, M. (2021). Social Vulnerability Index and NYC DOT's Bus Priority Corridors Comparative Analysis for New York City.[Online]. Available at:

https://public.tableau.com/app/profile/maitri5379/viz/SocialVulnerabilitylndexandNYCDOTsBusPriorityC orridorsComparativeAnalysisforNewYorkCity/MP Story)

The City of New York. (2019). OneNYC 2050[Online]. Available at: http://onenyc.cityofnewyork.us/

The Fourth Regional Plan. (2021). Create a dynamic, customer-oriented transportation network[Online]. Available at: http://fourthplan.org/action/transportation.

U.S. Department of Education. (2021). Federal TRIO Programs Current-Year LowIncome Levels[Online]. Available at: https://www2.ed.gov/about/offices/list/ope/trio/incomelevels.html 